\title{
Hypermagnesemia Induced by Massive Cathartic Ingestion in an Elderly Woman without Pre-existing Renal Dysfunction
}

\author{
Makoto KonTANI, Akinori HARA*, Shinji OHTA** and Takayuki IKEDA
}

\begin{abstract}
A 76-year-old woman was referred to our hospital for unresponsiveness and hypotension. She had developed constipation that had led to ileus and had received $34 \mathrm{~g}$ of magnesium citrate (Magcolol $\mathbf{P}^{\circledast}$ ) orally the day before. She was lethargic, her blood pressure was less than $\mathbf{5 0}$ $\mathrm{mmHg}$, and electrocardiogram (ECG) revealed sinus arrest with junctional escape rhythm. Her serum concentration of magnesium $(\mathrm{Mg})$ was markedly elevated $(16.6$ $\mathrm{mg} / \mathrm{dl}=13.7 \mathrm{mEq} / \mathrm{l}$ ). Emergency colonoscopy revealed ischemic colitis. As her condition ameliorated, her renal function returned to normal. Hence, the present case suggests that severe hypermagnesemia can occur in the absence of pre-existing renal dysfunction in elderly patients with gastrointestinal diseases.
\end{abstract}

(Internal Medicine 44: 448-452, 2005)

Key words: magnesium citrate, sinus arrest, hypotension, temporary atrial pacing, cardiac pacing threshold

\section{Introduction}

Hypermagnesemia is considered to be rare (1) and usually iatrogenic; occurring, for example, after intravenous $\mathrm{Mg}$ administration $(2,3)$, oral ingestion of $\mathrm{Mg}$-containing antacids or cathartics (4-7), or procedure-related retroperitoneal (8) or peritoneal $(1,9)$ leakage of $\mathrm{Mg}$-containing preparations. The kidney is the principal organ involved in Mg regulation (10), and therefore hypermagnesemia commonly occurs in the presence of renal failure. However, there have been several reports describing rare cases of symptomatic hypermagnesemia without pre-existing renal dysfunction $(5,7-9)$.
We describe such a patient who developed severe hypermagnesemia after oral ingestion of a massive Mg-containing cathartic.

\section{Case Report}

A 76-year-old woman was referred to our hospital on August 11, 2001, for unresponsiveness and hypotension refractory to catecholamines. Her past medical history was significant for postoperative myoma uteri, gastric ulcer and senile dementia. She had been admitted to another hospital for constipation on June 30, and had not defecated since August 6. She had received $34 \mathrm{~g}$ of magnesium citrate (Magcolol $\mathrm{P}^{\circledast}$; containing $2.71 \mathrm{~g}$ of $\mathrm{Mg}$ ) orally the day before referral. The next morning she was found to be lethargic and did not respond well to verbal stimuli [Japan Coma Scale (JCS) II-3]. Her blood pressure (BP) was less than 50 $\mathrm{mmHg}$. It responded transiently to intravenous epinephrine and dopamine, but soon fell again. Following this, she was intubated and transferred to our emergency department.

On admission to the emergency department, she was fully conscious (JCS I-1). Her temperature was $35.8^{\circ} \mathrm{C}$, with a BP of $92 / 49 \mathrm{mmHg}$ and a pulse rate of $107 / \mathrm{min}$ under dopamine administration. Her skin was moist and not cyanotic. No heart murmur, crackles or rubs were audible from her chest. Her abdomen was soft but distended, and tympanic and tender in the left lower quadrant. Bowel sounds were diminished. Laboratory data showed elevated inflammatory reactions (white blood cell count (WBC), 6,800/ $\mathrm{mm}^{3}$ (neutrophils, 82\%); C-reactive protein (CRP), $5.6 \mathrm{mg} / \mathrm{dl}$ ), renal insufficiency (serum urea nitrogen (BUN), $27.3 \mathrm{mg} / \mathrm{dl}$; serum creatinine (Crnn), $1.4 \mathrm{mg} / \mathrm{dl}$ ), and hypoproteinemia (total protein, $4.1 \mathrm{~g} / \mathrm{dl}$ ). Other laboratory values were as follows: hemoglobin, $11.8 \mathrm{~g} / \mathrm{dl}$; hematocrit, 39.4\%; platelet count, $15.5 \times 10^{4} / \mathrm{mm}^{3}$; fibrinogen; $220 \mathrm{mg} / \mathrm{dl}$; sodium, 132 $\mathrm{mEq} / l$; potassium, $3.0 \mathrm{mEq} / l$; calcium, $3.7 \mathrm{mEq} / l$; phospho-

From the Department of Cardiology, *the Department of Internal Medicine (Currently affiliated with Department of Cancer Gene Therapy, Kanazawa University, Graduate School of Medical Science and Department of Internal Medicine, Kanazawa) and **the Department of Surgery, Tsuruga Municipal Hospital, Tsuruga

Received for publication January 5, 2004, Accepted for publication November 19, 2004

Reprint requests should be addressed to Dr. Makoto Kontani, the Department of Cardiology, Tsuruga Municipal Hospital, 1-6-60 Mishima-cho,Tsuruga, Fukui 914-8502 


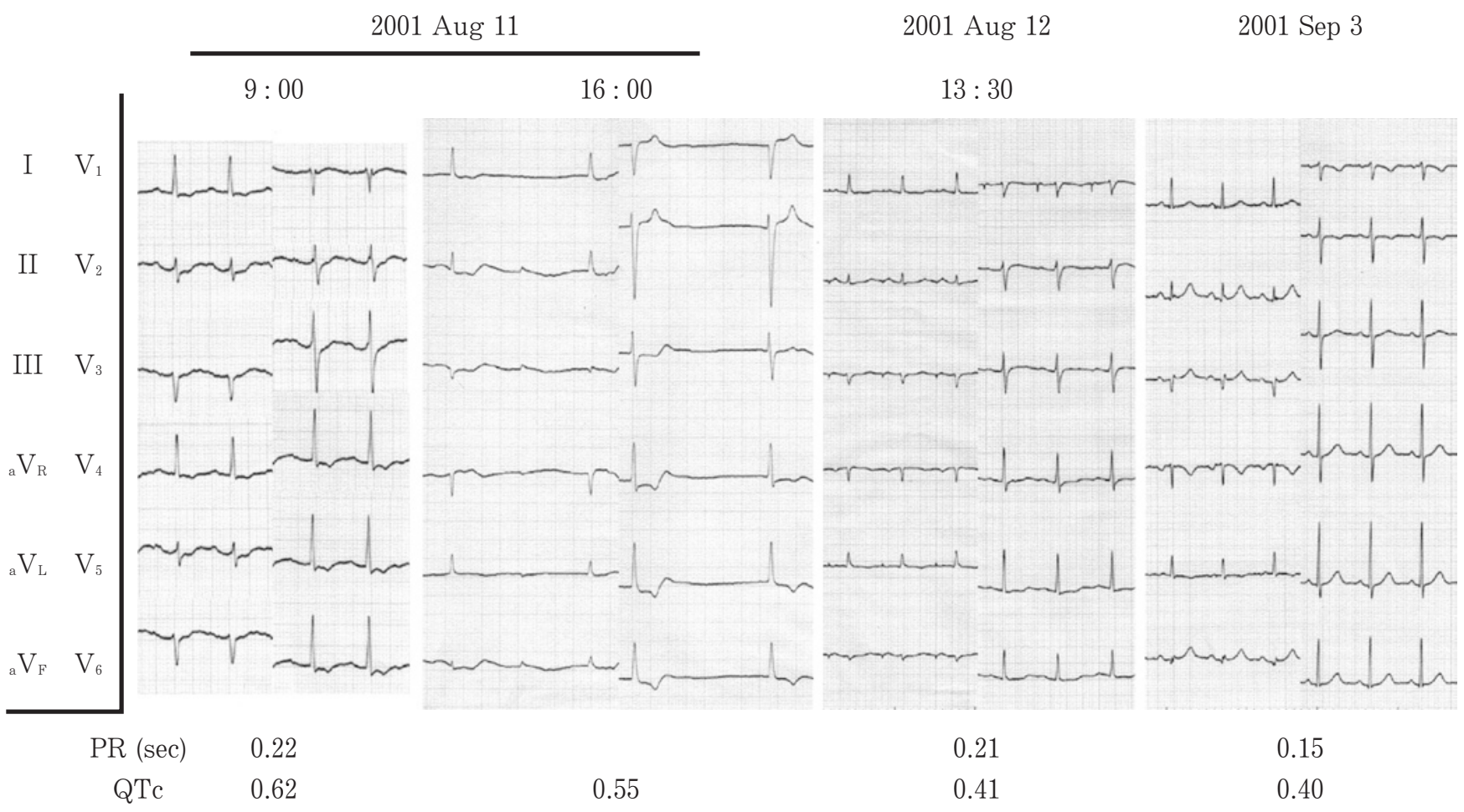

Figure 1. Serial changes in electrocardiographic findings (PR: PR interval, QTc: corrected QT interval).

rus, $2.7 \mathrm{mg} / \mathrm{dl}$; aspartate aminotransferase, $52 \mathrm{IU} / l$; alanine aminotransferase, $9 \mathrm{IU} / l$; lactate dehydrogenase, $289 \mathrm{IU} / l$; amylase, $792 \mathrm{IU} / l$; and albumin, $2.0 \mathrm{~g} / \mathrm{dl}$. Arterial blood gas analysis during inhalation of $\mathrm{O}_{2}$ at 3 liter/min showed the following: $\mathrm{pH}, 7.365 ; \mathrm{pO}_{2}, 146$ Torr; $\mathrm{pCO}_{2}, 43.1$ Torr; $\mathrm{HCO}_{3}$, $24.6 \mathrm{mEq} / l$; base excess, $-0.5 \mathrm{mEq} / l$; and $\mathrm{O}_{2}$ saturation, $100 \%$. ECG revealed sinus tachycardia, 1st degree atrioventricular block (PR interval $220 \mathrm{msec}$.), QT prolongation (QTc 619 msec.), and left axis deviation (Fig. 1). Computed tomography of the abdomen showed that the entire colon and rectum was filled with feces and fluid, which suggested the presence of ileus.

A diagnosis of fecal ileus was made and at first the patient's transient unresponsiveness and hypotension were ascribed to a vasovagal reaction to abdominal pain due to ileus. She was transferred to the ICU at 11:30 AM and was extubated and dopamine was withdrawn. At 2 : 00 PM, she became hypotensive and bradycardia occurred again, but she did not respond to intravenous atropine. Hypoventilation and lethargy became evident and her consciousness deteriorated. She was intubated again and required mechanical ventilation. Intravenous catecholamines (norepinephrine and isoproterenol) were started, but her BP and HR did not rise (Fig. 2). An ECG revealed sinus arrest with junctional escape rhythm (Fig. 1). Thereafter, other causes for bradycardia and hypotension had to be explored, and since she had received a massive Mg-containing cathartic the day before despite severe bowel obstruction, the presence of hypermagnesemia was suspected.
Data from blood drawn at 8 : 30 PM showed a markedly elevated serum $\mathrm{Mg}$ concentration of $12.4 \mathrm{mg} / \mathrm{dl}(=10.2 \mathrm{mEq} /$ $l$ ) and the diagnosis of symptomatic hypermagnesemia was confirmed. The serum $\mathrm{Mg}$ concentration on admission was $16.6 \mathrm{mg} / \mathrm{dl}(=13.7 \mathrm{mEq} / \mathrm{l})$. Hemodialysis was contraindicated because of severe hypotension, so we first attempted to clear the residual $\mathrm{Mg}$ from her bowels with an enema and emergency colonoscopy. Colonoscopy revealed ischemic colitis in the descending and sigmoid colon. Temporary cardiac pacing was then attempted: we tried to pace the right atrium to maximize the increase in cardiac output and blood pressure. The high right atrial (HRA) pacing threshold was $12 \mathrm{~V}$ and that of the right ventricle was $6 \mathrm{~V}$, both of which were markedly elevated. It did not occur to us to use intravenous calcium.

HRA pacing resulted in $1: 1$ atrioventricular conduction, elevation of systolic BP to over $70 \mathrm{mmHg}$, and HR elevation (pacing rate at 80 to 90 beats/min), which were accompanied by diuresis. Thereafter, her serum $\mathrm{Mg}$ concentration gradually declined to normomagnesemia without hemodialysis along with changes in serum Crnn and BUN (Fig. 2). She returned to a sinus rhythm about 24 hours after atrial pacing had been started, at which time the serum $\mathrm{Mg}$ level was presumed to be between 5.7 and $9.9 \mathrm{mg} / \mathrm{dl}$. The rate of decline in her serum $\mathrm{Mg}$ concentration exhibited a logarithmic-like decay (Fig. 2), as previously demonstrated (7).

In the convalescent phase, ECG revealed a normal sinus rhythm (Fig. 1). A coronary arteriogram showed no significant coronary artery stenosis, a left ventriculogram showed 


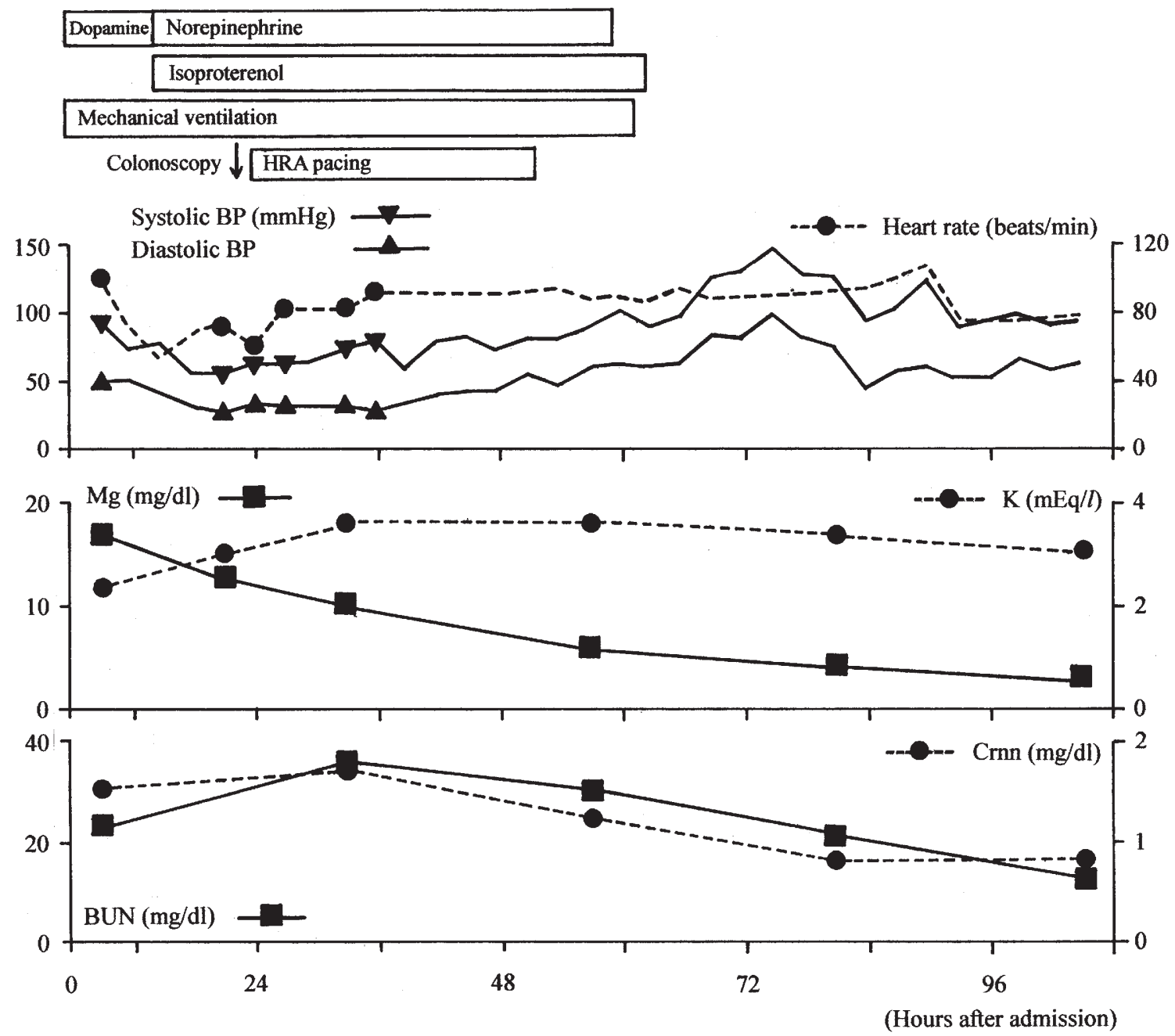

Figure 2. Schematic presentation of the clinical course of this case (BP: blood pressure, BUN: blood urea nitrogen, Crnn: serum creatinine, HRA: high right atrial, K: potassium, Mg: magnesium).

normal wall motion, and a cardiac electrophysiologic study, performed when the serum concentration of $\mathrm{Mg}$ was 1.96 $\mathrm{mg} / \mathrm{dl}$ and those of BUN, Crnn, and K were $11.6 \mathrm{mg} / \mathrm{dl}, 0.5$ $\mathrm{mg} / \mathrm{dl}$, and $4.1 \mathrm{mEq} / \mathrm{l}$ respectively, showed normal intracardiac conduction and refractoriness. The HRA pacing threshold was $1.5 \mathrm{~V}$ and that of the right ventricle was $4.5 \mathrm{~V}$.

The patient made a full recovery and was discharged without sequelae and without recurrence of hypermagnesemia.

\section{Discussion}

$\mathrm{Mg}$ is the fourth most abundant cation in the human body (about $1,000 \mathrm{mmol}$, or $23 \mathrm{~g} /$ body). About half of the total body $\mathrm{Mg}$ is in bone, and extracellular $\mathrm{Mg}$ accounts for only around $1 \%$ (10). Approximately one-third of extracellular $\mathrm{Mg}$ is protein bound (primarily to albumin), while the remaining two-thirds of ionized $\mathrm{Mg}^{2+}$ can diffuse into the kidneys (11). Mg homeostasis is dependent mainly on gastrointestinal absorption and renal excretion, and the kidney is the principal organ involved in $\mathrm{Mg}$ regulation. About 1,800 $\mathrm{mg}$ of $\mathrm{Mg}$ is filtered into the glomeruli daily (12), and is then reabsorbed, mainly in the thick ascending limb of Henle (60$70 \%$ of filtered $\mathrm{Mg}^{2+}$ ) and the distal tubule (10\%) (10). Renal $\mathrm{Mg}$ excretion is very efficient because the thick ascending limb of Henle has the capacity to completely reject $\mathrm{Mg}$ reabsorption under conditions of hypermagnesemia (4), and hence the maximal renal excretion of more than $6 \mathrm{~g} /$ day (500 $\mathrm{mEq} / \mathrm{day}$ ) can occur (8). Therefore, hypermagnesemia commonly arises in the presence of renal failure.

The major gastrointestinal site for $\mathrm{Mg}$ absorption is the upper small bowel $(11,12)$ and its mechanism of regulation is mainly through passive diffusion (10). Since one-third of orally ingested $\mathrm{Mg}$ is absorbed normally $(8,11)$, massive oral $\mathrm{Mg}$ ingestion may result in hypermagnesemia if the absorbed amount of $\mathrm{Mg}$ exceeds the renal excretion capacity. 


\section{Hypermagnesemia Induced by Cathartic}

Table 1. Manifestations of Hypermagnesemia in Relation to Serum Mg Levels (Adopted from References 3 and 8)

\begin{tabular}{lll}
\hline \multicolumn{2}{c}{ Serum Mg level } & \\
\cline { 1 - 2 } $\mathrm{mg} / \mathrm{dl}$ & $\mathrm{mEq} / \mathrm{l}$ & \\
\cline { 1 - 2 } $1.7-2.4$ & $1.4-2.1$ & Normal serum level \\
$5-8$ & $4-7$ & Nausea, vomiting, cutaneous flushing, bradycardia, hypotension \\
$9-12$ & $8-10$ & Absent deep tendon reflexes, somnolence \\
$>15$ & $>12$ & Respiratory depression, paralysis, complete heart block \\
$>20$ & $>16$ & Cardiac arrest in asystole \\
\hline
\end{tabular}

The patient in the present case exhibited severe symptomatic hypermagnesemia with sinus arrest, hypotension, respiratory depression and a depressed mental state (Table 1). These symptoms were rapidly ameliorated along with a decrease in the serum $\mathrm{Mg}$ concentration soon after BP was raised through temporary atrial pacing, which resulted in diuresis. The patient's renal function was, however, found not to be impaired when evaluated during the convalescent phase. Serum levels of Crnn and BUN were elevated at the initial presentation and in the clinically exacerbated phase, but returned to normal ranges, along with that of the $\mathrm{Mg}$, as she became hemodynamically stable (Fig. 2). These data suggest that the patient's renal dysfunction at presentation was attributable to prerenal factors (probably mainly due to hypotension and reduced cardiac output, and perhaps also to intravascular dehydration due to hypoalbuminemia), and of a reversible nature. Hypermagnesemia can cause hypotension and reduced cardiac output due to bradycardia, leading to reduced renal blood flow, reduced glomerular filtration, and thus reduced clearance of urinary $\mathrm{Mg}$. These processes can create a vicious cycle that leads to a prerenal type of renal dysfunction and exacerbation of hypermagnesemia. In particular, older persons are likely to be susceptible to these processes because renal function is physiologically reduced in the elderly.

The patient had received a massive amount of $\mathrm{Mg}$, approximately $2.71 \mathrm{mg}(223 \mathrm{mEq})$, in one dose on the day before admission to our hospital. Moreover, she had suffered severe constipation leading to ileus for at least 5 days, and hence the orally ingested $\mathrm{Mg}$ had stayed in the intestine much longer and intestinal absorption of $\mathrm{Mg}$ might have been enhanced. Hypermagnesemia itself can cause bowel hypomotility through blockade of myenteric neurons and interference with excitation-contraction coupling of smooth muscle cells (12), and this might have exacerbated ileus. Ischemic colitis might also have altered mucosal integrity and enhanced $\mathrm{Mg}$ absorption. These non-renal factors may have contributed to the development of hypermagnesemia in the patient without pre-existing renal dysfunction.

We were also able to demonstrate the effect of hypermagnesemia on the cardiac pacing threshold. During hypermagnesemia, both atrial and ventricular pacing thresholds were markedly increased, but these were within normal ranges when a cardiac electrophysiologic study was performed under conditions of normomagnesemia. The results of studies on the electrophysiologic effects of hypermagnesemia are conflicting (13-15), but to our knowledge, this is the first case report to show that hypermagnesemia can cause an increased cardiac pacing threshold, at least in the severe cases.

In summary, we described an elderly woman without preexisting renal dysfunction who developed severe hypermagnesemia after oral ingestion of a massive $\mathrm{Mg}$-containing cathartic. She had developed ileus and ischemic colitis prior to onset of hypermagnesemia. This case suggests that severe hypermagnesemia can occur in the absence of pre-existing renal dysfunction in patients with gastrointestinal diseases, particularly if the patient is elderly. We were also able to demonstrate the acute effect of hypermagnesemia on the cardiac pacing threshold.

\section{References}

1) Clark BA, Brown RS. Unsuspected morbid hypermagnesemia in elderly patients. Am J Nephrol 12: 336-343, 1992.

2) Morisaki H, Yamamoto S, Morita Y, Kotake Y, Ochiai R, Takeda J. Hypermagnesemia-induced cardiopulmonary arrest before induction of anesthesia for emergency Cesarean section. J Clin Anesth 12: 224-226, 2000.

3) Vissers RJ, Purssell R. Iatrogenic magnesium overdose: two case reports. J Emerg Med 14: 187-191, 1996.

4) Schelling JR. Fatal hypermagnesemia. Clin Nephrol 53: 61-65, 2000.

5) McLaughlin SA, McKinney PE. Antacid-induced hypermagnesemia in a patient with normal renal function and bowel obstruction. Ann Pharmacother 32: 312-315, 1998.

6) Ferdinandus J, Pederson JA, Whang R. Hypermagnesemia as a cause of refractory hypotension, respiratory depression, and coma. Arch Intern Med 141: 669-670, 1981.

7) Zwerling H. Hypermagnesemia-induced hypotension and hypoventilation. JAMA 266: 2374-2375, 1991.

8) Fassler CA, Rodriguez RM, Badesch DB, Stone WJ, Marini JJ. Magnesium toxicity as a cause of hypotension and hypoventilation, occurrence in patients with normal renal function. Arch Intern Med 145: 1604-1606, 1985

9) Mordes JP, Swartz R, Arky RA. Extreme hypermagnesemia as a cause of refractory hypotension. Ann Intern Med 83: 657-658, 1975.

10) Weisinger JR, Bellorin-Font E. Magnesium and phosphorus. Lancet 352: 391-396, 1998.

11) Whang R. Clinical disorders of magnesium metabolism. Compr Ther 23: $168-173,1997$. 


\section{KONTANI et al}

12) Mordes JP, Wacker WEC. Excess magnesium. Pharmacol Rev 29: 273-300, 1978.

13) Keren A, Dorian P, Davy JM, Opie LH. Effects of magnesium on ischemic and reperfusion arrhythmias in the rat heart and electrophysiologic effects of hypermagnesemia in the anesthetized dog. Cardiovasc Drugs Ther 2: 637-645, 1988.
14) DiCarlo LA Jr, Morady F, de Buitleir M, Krol RB, Schurig L, Annesley TM. Effects of magnesium sulfate on cardiac conduction and refractoriness in humans. J Am Coll Cardiol 7: 1356-1362, 1986.

15) Hall SK, Fry CH. Magnesium affects excitation, conduction, and contraction of cardiac muscle. Am J Physiol 263 (2 pt 2): H622-633, 1992. 